\title{
Do Pessoal do Ceará ao Movimento Cabaçal: O "local" e o "global" na música cearense
}

Del Pessoal do Ceará al Movimiento Cabaçal: El "local” y el "global” en la música de Ceará

\section{From Pessoal do Ceará to the Cabaçal Movement: The "local" and the "global" in the music of Ceará}

\author{
Jane Meyre Silva Costa ${ }^{1}$
}

Palavras chave:

Neste artigo me proponho a discutir três movimentos artísticoculturais no campo musical no Nordeste e, especificamente, no Ceará.

Música A "música nordestina" se traduz como uma manifestação cultural de músicos cearenses, caracterizados pelo hibridismo cultural,

Cultura configurando uma "nova" estética musical, que utiliza uma linguagem

Nordeste plural, realizando a mistura de ritmos. De uma maneira geral, esses movimentos podem significar tanto a busca de uma "identidade local" em meio ao processo de globalização cultural, através do diálogo com a "cultura popular nordestina", quanto a possibilidade de articular novos sentidos, estilos de vida, valores e comportamentos que estabelecem um diálogo entre a música "local" e "global". 


\begin{abstract}
Resumen:
En este artículo me propongo discutir tres movimientos artísticoculturales en el campo de la música en el Nordeste y, específicamente, en Ceará. La "música del Nordeste" se traduce en una manifestación cultural de músicos de Ceará, caracterizados por el hibridismo cultural, configurando una "nueva" estética musical, la que utiliza un lenguaje plural, realizando la mezcla de ritmos. En general, esos movimientos pueden significar tanto la búsqueda de una "identidad local" en el proceso de la globalización cultural, a través del diálogo con la "cultura popular del Noreste", como la posibilidad de articular nuevos sentidos, estilos de vida, valores y comportamientos que establecen un diálogo entre la música "local" y "global".
\end{abstract}

\section{Palabras clave:}

Música

Cultura

Nordeste

\section{Keywords:}

Music

Culture

Northeast

\section{Abstract:}

In this article I propose to discuss three artistic and cultural movements in the music field in the Northeast and, specifically, in Ceará. The "northeastern music" translates into a cultural manifestation of musicians from Ceará, characterized by the cultural hybridity, setting up a "new" musical aesthetic, which uses a plural language, carrying out the mix of rhythms. Generally, these movements can mean both the search for a "local identity" in the process of cultural globalization, through the dialogue with the "northeastern popular culture", and the possibility of articulating new meanings, lifestyles, values and behaviors that establish a dialogue between the "local" and the "global" music. 


\section{Do Pessoal do Ceará ao Movimento Cabaçal: O "local" e o "global" na música cearense}

Fortaleza, no decorrer das décadas, vêm despontando como pólo cultural formador de personalidades da música como Humberto Teixeira, Luis Assunção, Fagner, Belchior, Ednardo, entre outros, que se tornaram ícones da música cearense no espaço nacional.

$\mathrm{Na}$ atualidade, esta cidade não fica atrás na representatividade com a música. Após dois movimentos que despertaram Fortaleza, para atividade artístico-musical, nos anos 70 com Massafeira e Pessoal do Ceará, vem o Movimento Cabaçal, realizando uma discussão diferenciada em torno da música, "cultura nordestina" e sua hibridação cultural.

Este artigo abordará então, esta efervescência cultural que teve início em meados da década de 1970, no Ceará e culminou com o Movimento Cabaçal nos anos 2000.

\section{1 - O "PESSOAL DO CEARÁ"}

Este movimento representou um novo momento na música popular brasileira na década de 1970, apesar deste nome não ter sido escolhido pelos próprios participantes do movimento (Rogério, 2008), e sim, por uma indústria fonográfica que necessitava rotular estes artistas provenientes do Ceará, significou uma geração de artistas que abriu caminhos para a música produzida no nordeste.

Apesar de existirem objetivos diferenciados dos diversos integrantes, o que os unia era a proposta de um processo de profissionalização artística no Ceará, tendo em vista um conhecimento e reco- nhecimento do público. Significou a participação de mais de cem artistas cearenses, que deu origem ao disco denominado "Pessoal do Ceará: meu corpo, minha embalagem todo gasto na viagem".

O ingresso dos compositores cearenses no mercado fonográfico se originou devido uma fase propícia pós-tropicalista ${ }^{2}$ (PIMENTEL, 2006), para o desenvolvimento de novos compositores e musicalidades. A "música regional" neste momento emergia como força de expressão, o que trouxe consequentemente uma rotulação de expressões para os músicos originários do Nordeste.

Da mesma forma que na década de 1980 ocorreu uma explosão de bandas de rock, na década de 70 ocorre o mesmo com a "música nordestina", traduzido desta forma pela indústria fonográfica, visando um amplo mercado em expansão.

Carvalho (2005) comenta sobre a indústria fonográfica em formação, que apóia e investe neste mercado cultural por achar que representa um novo artigo em expansão. Apoiadas por muitas gravadoras, o falar do nordeste e o sotaque são contundentes na identificação das chamadas "bandas regionais".

A estratégia é tentar resistir ao tempo com a agilidade do improviso, a musicalidade da rima, a camisa de força da métrica, o forte sotaque nordestino, a voz anasalada da herança medieval e toda a riqueza de uma tradição popular que se apropria da indústria do entretenimento. (CARVALHO, 2005, p. 69)

$\mathrm{Na}$ realidade, o sistema capitalista tem grande influência em toda essa transformação que está ocorrendo, especificamente na música. Por ser bastante multifacetado, se adapta a todas as manifestações, desde que lucrativas para o empreendedor. O mercado encara essas 
"novas" manifestações como um produto inédito para o consumo de pessoas que não se adequaram ao mercado já existente. Canclini (1997) comenta sobre este fato dando, assim, quatro alternativas principais para o que está acontecendo:

01. A impossibilidade de incorporar toda a população à produção industrial urbana;

02. A necessidade de o mercado incluir as estruturas e os bens simbólicos tradicionais nos circuitos massivos de comunicação, para atingir mesmo as camadas populares menos integradas à modernidade;

03. Ao interesse dos sistemas políticos em levar em conta o folclore a fim de fortalecer sua hegemonia e sua legitimidade;

04. A continuidade na produção cultural dos setores populares. (CANCLINI, 1997: p.215)

O autor descreve, ainda, sobre a necessidade desse tipo de indústria cultural que se ocupa, também, dos consumidores resistentes ao consumo uniforme, diversificando a produção de meios para se adaptar a todos os estilos e anseios. Com isso, o tradicional/regional/popular é transformado, interagindo com o moderno/urbano/globalizado, e demonstrando, assim, que o mercado cultural também tem que se apropriar dos consumidores em busca de novos valores culturais.

A partir desta concepção de "música cearense", Pimentel (2006) desenvolve em seu estudo uma série de aspectos que revela serem distintivos e identificadores da música local. O primeiro aspecto é a urbanidade como código referencial e existencial, trazendo consigo as diversas influências culturais da cidade para suas músicas e composições. O segundo é a relação com a contemporaneidade. Em sua análise, a maioria das músicas vindas do Ceará representa uma visão do cotidiano de cada compositor, que traz um olhar universal à sua música, falando de seu tempo e das transformações históricas ocorridas:

Os compositores cearenses revelaram a necessidade de assumir um compromisso com sua realidade: o compromisso de uma geração frente aos impasses e contradições próprias do momento histórico advindos com as transformações culturais operadas não só em nível nacional como em nível mundial, que colocaram em evidência a revolução dos costumes, dos padrões sexuais e morais. (PIMENTEL, 2006, p. 161)

Dentre esses compositores a autora cita Belchior, que denuncia em suas letras um olhar crítico sobre a juventude de seu tempo. Com o trecho da música Velha roupa colorida: "E o que em algum tempo, era jovem e novo, hoje é antigo, e precisamos todos rejuvenescer (...)", ela exemplifica que um dos segmentos utilizados para caracterização da denominada "identidade cearense" é sua relação com os movimentos contraditórios da sociedade. No trecho que citei acima, quando Belchior fala em "rejuvenescer", indaga sobre a mudança de tempo, vinculando, assim, sua relação com os movimentos contraditórios da contemporaneidade.

Segundo Mary Pimentel (1995), esse movimento representou um marco na incursão dos novos compositores cearenses dentro do mercado fonográfico, tendo como alguns de seus participantes o cantor e compositor Raimundo Fagner. Essa geração buscou a valorização da música popular cearense, que começava a apontar para o Sudeste - no eixo Rio-São Paulo - ainda que através de trabaIhos individualizados.

Por último, como terceiro traço distintivo da música cearense, temos a rela- 
ção amorosa entre o artista e seu lugar de origem. Segundo a autora, "sem levantar bandeiras ou apelar para ufanismos ou bairrismos, o compositor cearense extravasa-se numa lúcida emoção ao mostrar a realidade cearense." (2006:164).

A autora utiliza como exemplo caracterizador da música cearense um trecho da música Terra, de Ednardo, "Eu venho das dunas brancas, onde eu queria ficar (..) meu céu é pleno de paz, sem chaminés ou fumaça". Verificamos que é evidente a demonstração de orgulho do compositor por sua terra de origem. Procurou mostrar seu ambiente como exemplo de paz e tranqüilidade, para onde ele desejaria permanecer. O artista cearense, também, foi um dos grandes mentores de outro movimento que surgiu no Ceará, no final da década de 1970: o Massafeira.

Não percebo, em suas músicas, uma característica peculiar pelo fato de serem realizadas no Ceará, o que eles buscam é descrever a realidade vivida na região. Os três elementos tratados pela autora para descrever este movimento, como a urbanidade, a relação dos artistas com a contemporaneidade e, finalmente, a ligação ao local de origem, estão presentes, também, nas diversas canções do Movimento Cabaçal, o qual me deterei posteriormente.

A globalização, sem dúvida, carrega esse embate, que faz com que a "cultura nordestina" absorva as mudanças do mundo atual, em constante transformação, não só no campo econômico, mas em toda a produção artística. É um ponto crucial a ser discutido, na tentativa de apontar os possíveis efeitos que esse mundo venha suscitar nos modelos já fixados da tradição.

No final da década de 1970, novos caminhos para a música cearense se abriam para outros artistas e compositores, e assim nasce o Massafeira Livre.

\section{2 - MASSAFEIRA LIVRE}

Um movimento cultural no final da década de 70 expressa muito bem a veia artística dos jovens músicos cearenses em busca de uma recriação estética e sua expansão no decorrer das décadas, o Movimento Massafeira.

O Massafeira Livre foi o nome do evento que ocorreu há 33 anos, de 15 a 18 de março de 1979, no Theatro José de Alencar, onde aconteceu o último movimento artístico cearense coletivo que teve um certo destaque no Brasil.

Originados em grandes encontros de músicos, compositores, poetas, artistas plásticos, escritores, cineastas, e tantas outras áreas ligadas às artes e diversas gerações de artistas do nordeste, este evento reuniu desde os artistas plásticos, passando pelos poetas até os músicos em quatro dias, "como se fosse o carnaval mudando de data e mais verdadeiro" como está impresso na contra capa do álbum homônimo, na perspectiva de "som, imagem, movimento e gente" como anunciava o criativo cartaz do evento idealizado pelo letrista e arquiteto Brandão ${ }^{3}$.

Em uma entrevista cedida ao jornal O Povo, Ednardo ${ }^{4}$, um dos integrantes do Massafeira e remanescente do Pessoal do Ceará, afirmou que este evento foi uma espécie de Woodstock tupiniquim, e pela primeira vez se assisti as mais variadas performances artísticas no palco. De todas as apresentações, além dos shows musicais, a que mais marcou na época foi o recital de Patativa do Assaré ${ }^{5}$, como relata Ednardo em outra entrevista para o jornal, O Globo em 1982:

Guardadas as proporções de divulgação nacional, o enfoque e abordagens, Massafeira é um projeto coletivo tão importante e revolu- 
cionário como a Semana de Arte Moderna de 1922, ou o Tropicalismo. Há todo uma proposta estética nova ali, um projeto coletivo amplo, que o diferencia de outros também importantes ${ }^{6}$.

Ednardo, então, descreve o evento Massafeira como:

A Massafeira foi uma das mais ousadas e seminais iniciativas de mostrar ao país o que estava acontecendo em termos de arte contemporânea espontânea e enraizada. Foi uma grande feira cultural que juntou música, artes plásticas, literatura, teatro, dança, cinema, artesanato e culinária. Eram mais de 300 artistas reunidos no Theatro José de Alencar, em março de 1979. Depois, foram mais de 200 músicos na gravação do disco duplo no Rio de Janeiro. Em seguida, mais de 150 artistas se juntaram para lançar o disco duplo no Theatro José de Alencar, em outubro de 1980. Muito pouco se falou no Ceará e no Brasil da importância da Massafeira? ${ }^{7}$.

Com isso, percebe-se o desejo desde décadas atrás, de artistas cearenses em revolucionar o espaço cultural do estado. Apesar da pouca repercussão nacional, o evento Massafeira Livre representou a transformação no cenário artístico cearense e pôde com isso originar seguidores que apesar de não terem participado ou até mesmo nascido nesta época, têm a mesma proposta do encontro: o desejo de renovação da música cearense e o diálogo com seu local de origem.

\section{O principal objetivo do Massafei-} ra era consolidar uma produção artística no Estado, não somente no campo musical, mas nas artes em geral. Seu desejo era sair do Sudeste, de onde tinha migrado na época de sua participação junto ao Pessoal do Ceará, que é onde centram as principais produções artísticas do país, e encontrar mercado, aqui, no Ceará. A propósito disso, é que mais de duas centenas de artistas cearenses chegaram a ser reunir no Theatro José de Alencar, no ano de 1979, na busca da consolidação de uma música cearense que dialogasse com o mundo contemporâneo.

Este movimento trouxe uma nova proposta para a música e compositores originários do Ceará, onde não sentiram a necessidade de sair do Ceará e migrar para o eixo Rio-São Paulo para apresentar suas canções. Implicou neste sentido a abertura e descentralização na música.

Percebo a necessidade destes dois movimentos originários no Ceará, da discussão sobre o diálogo entre referências "locais" e "globais". Cada um com sua especificidade musical pretendeu abrir uma discussão sobre a referenciada "música nordestina" tomada pela indústria fonográfica, como "regional", em contraposição a música do eixo Rio-São Paulo tida como "nacional".

A linguagem da música é universal, não podemos restringi-la a apenas elementos tipificadores de uma região em específico, e foi isso que estes movimentos quiseram discutir a partir de suas produções. Para fazer música no Nordeste, não necessitamos obrigatoriamente falar sobre seca, saudade, sertão pois estes elementos dialogam com a cultura "global", novos elementos da cidade contemporânea se entrelaçam a estas representações trazendo um novo olhar para a música construída no Nordeste.

E é desta forma, que estes movimentos ocorridos nas décadas de 70-80 influenciam, jovens nos anos 2000, que revigoram esta discussão, trazendo um olhar global aos elementos locais da cultura cearense, o Movimento Cabaçal. 
NOS ANOS 2000: NASCE O MOVIMENTO CABAÇAL

O Movimento Cabaçal iniciou-se em 2001, encabeçado por jovens cearenses da zona urbana do Estado, tendo como proposta fundamental a valorização da "cultura regional nordestina". Uma de suas características principais é a utilização de instrumentos e ritmos provenientes de bandas cabaçais ${ }^{8}$, como o pífano, a zabumba, as sanfonas e as alfaias, aliados a sons e a instrumentos do universo pop rock, próprios da cultura contemporânea, como guitarras, baixos e baterias.

Junto à opinião pública, a impressa local, à época, fez grande menção aos grupos, com matéria realizada pelo jornal O Povo ${ }^{9}$, publicada logo após os eventos no Dragão do Mar, referindo-se a um dos shows que mais reuniu o maior número de público, no que diz respeito aos artistas cearenses, como se vê:

Foi justamente do encontro de integrantes do Jumentaparida e DZefinha, num estúdio de televisão, que se deu o início de uma conversa que acabou gerando o Movimento Cabaçal. $\mathrm{O}$ nome surgiu em homenagem às bandas cabaçais do Cariri, que preservam uma sonoridade característica. Rapidamente, bandas e artistas de outras manifestações artísticas-teatro, dança, artes plásticas, literatura etc foram se engajando ao movimento, numa série de shows do Cabaçom, que acabaram por reunir ainda Jumentaparida, DZefinha, mais Soul Zé e a caririense Dr. Raiz. De lá o Movimento só se expande. O maior deles, na praça Almirante Barroso, ao lado do Centro Dragão do Mar, as bandas reuniram o maior público para artistas cearenses naquele local (três mil pessoas), segundo a produção do Centro Cultural. (site www.noolhar.com/opovo/vidaearte)
O jornal tece, ainda, comparações com o Pessoal do Ceará ${ }^{10}$, movimento de amplitude nacional que, trinta anos atrás, revolucionou o cenário cearense. A saber:

Pavimentando a ponte musical que liga essas duas gerações da música cearense estão o resgate e a valorização de elementos da cultura regional sob um prisma universal. Mas além desse pressuposto que foi utilizado tanto por Ednardo, Fagner e cia, quanto pela bandas e artistas que hoje compõem a estética cabaçal, ambos os movimentos têm um disco síntese. (jornal O Povo; 2003).

As bandas chamavam-se DZefinha, SoulZé, Jumenta Parida e Dr Raiz. A proposta seria aliar ao seu estilo musical característico - o hardcore, o soul - o baião, coco, e o teatro popular, além do uso de instrumentos típicos de bandas cabaçais $^{11}$ como a zabumba, o pífaro, as alfaias, triângulo, pandeiros, derivando daí a origem do Movimento em si.

Um dos elementos referentes ao tradicional, aos quais os jovens se referem, e que gerou a própria denominação do Movimento Cabaçal, é a banda Cabaçal dos Irmãos Aniceto ${ }^{12}$.

A união destas bandas originou um cd, em abril de 2002, intitulado CABAÇOM, A Mostra de Música do Movimento Cabaçal que tem em sua composição, quatro músicas de cada banda (Dzefinha, Jumentaparida, SoulZé e Dr Raiz) dando início a uma série de eventos culturais.

É importante entendermos a "mundialização" cultural como um termo indispensável na compreensão da proposta do Movimento Cabaçal. Com base nesse conceito, percebo, através da leitura de alguns estudiosos sobre o tema, uma nova forma de conceber a cultura dentro da sua proposta: a "desterritorialização". Ao 
mesmo tempo em que os jovens artistas procuravam valorizar a "cultura nordestina", se "desterritorializam" do seu local de origem para que possam dialogar com a cultura mais "globalizada". O termo se ajusta, portanto, à saída do espaço individualizado, para conquistar outro, de sentido mais abrangente.

Os autores Canclini (1997), Hall (2003) e Ortiz (2001), que pesquisaram sobre a fusão entre diversas esferas culturais, tratam do termo "desterritorialização" não como sendo um afrouxamento da cultura de seu local de origem. Apesar de manter sua gênese, será cada vez mais difícil sustentá-la integralmente devido ao processo globalizante e suas confluências com outras culturas.

Com a "desterritorialização" elimina-se, portanto, o enorme peso que as raízes e a tradição exercem sobre a sociedade, permitindo que haja uma mobilidade dos elementos culturais. Essa é a maneira pela qual a cultura se "esvazia" de seus conceitos particulares.

Canclini (1997), fazendo um estudo comparativo, discorre sobre a existência de uma tensão entre os processos de "territorialização" e "desterritorialização", isto é, entre as perdas das referências com relação aos aspectos tradicionais e a configuração de encadeamento cultural. Essa última é geradora de uma gama de possibilidades, no que se refere à articulação entre a urbe e o processo de mundialização, o que dá margem a uma nova configuração cultural.

O conflito referido pelo autor está presente na mentalidade dos jovens envolvidos no Movimento Cabaçal, visto que, ao mesmo tempo em que alguns se voltam para temas universais, referem-se ao Nordeste e ao Ceará, em particular, como fontes que devem se manter preservadas.
A "mundialização" maximiza esse conflito. Ao mesmo tempo em que o homem contemporâneo tem necessidade de estar aberto às novidades tecnológicas embora haja os mais resistentes a toda e qualquer mudança - existe um outro ponto a se questionar, que é o da busca por algo que o "identifique" como único, em meio a uma diversidade cultural. Penso ser esse o motivo principal do surgimento de grupos como o Movimento Cabaçal.

A primeira banda, denominada $\mathrm{Dr}$. Raiz, originária de Juazeiro do Norte, em 1998, tem como alvo principal a fusão de elementos do rock com os da chamada "cultura popular nordestina". Quanto ao nome, foi idéia do próprio vocalista Júnior Boca, devido a um cordel de Patativa do Assaré, em que ressalta um personagem com essa denominação:

A gente estava procurando algo que tivesse a ver com "raízes", e aí a gente lembrou do cordel do Patativa do Assaré, e da própria figura do Dr. Raiz. trata-se de um personagem que vive nas feiras livres, vendendo ervas medicinais, às pessoas. A gente achou legal, levou lá...e todo mundo aceitou. (Júnior Boca, Dr. Raiz)

A Banda Dr Raiz lança um $C D$, no ano de 2006, intitulado Cariri.Ce.Brasil, trazendo uma seleção de 17 músicas. Sua fonte de inspiração, segundo eles, são as manifestações culturais populares, como os reisados, as lapinhas, os pastoris, o ritmos das bandas cabaçais, o forró pé-de-serra, o maracatu, o coco, o maneiro-pau, a embolada e a cantoria. Assim como a banda Dzefinha, Dr.Raiz também utiliza performances teatrais em seus shows. Em uma das músicas intitulada Caldeirão, o cantor Júnior Boca se veste de Beato José Lourenço ${ }^{13}$ e realiza uma pequena encenação no palco.

Os integrantes que constituem a banda Dr.Raiz, em sua maioria, são pro- 
venientes da cidade de Juazeiro do Norte, talvez seja por esse motivo que apesar da influência sobre a Banda de elementos da cultura rock ${ }^{14}$, em suas composições melódicas, percebemos a caráter influenciador da terra de origem, Juazeiro do Norte localizado na região do Cariri no Ceará. Local este, que tem uma grande expressão cultural de seus artistas, além de enorme presença de manifestações artísticas e folguedos nordestinos. Traz assim para a banda o caráter híbrido presente em suas composições.

A segunda banda, também nascida no interior do estado do Ceará, Banda Dzefinha, originária de Itapipoca, apareceu no cenário cearense em 2001. Vem com uma proposta de integrar música e teatro, devido aos espetáculos de rua, na cidade. Em suas apresentações realiza uma interação com a platéia através de brincadeiras e "contações" de histórias e "causos" populares.

Da experiência teatral dos três irmãos - Orlângelo Leal, Paulo Orlando e Ângelo Marcio - que tinham, anteriormente, uma companhia de teatro no início da carreira - migraram para outra linha artística: a música. Levaram consigo a "performance" corporal adquirida no teatro, verdadeiro diferencial da banda: "O teatro na música".

A Banda lançou no mercado o primeiro Cd intitulado Cantos e Causos. O álbum compõe-se de 12 faixas musicais. Sua vendagem já foi esgotada. Tem como freqüente em suas músicas, neste primeiro $C D$, segundo os próprios integrantes, a presença de três elementos principais: o cômico, rítmico e a dança popular.

\section{O segundo $C D$ intitulado Zefinha} Vai à Feira vem com uma proposta, a meu ver, bastante diferente da anterior. Pelo próprio título criado, Orlângelo Leal explica o objetivo desse segundo traba-
Iho "A feira que batiza o cd é exatamente uma metáfora para o mundo. Para aparecer em meio à turba provocada pela globalização, marcada pelo consumismo desenfreado, é preciso também entrar no jogo do mercado. Globalização é se ofertar para o mundo."15

As duas bandas cujos integrantes eram da cidade de Fortaleza, eram: Jumentaparida e SoulZé. A primeira banda, fundada em 1998, era reconhecida como sendo o Hardcore Regionalista, por ter uma preponderância mais intensa da cultura rock. A constante presença das guitarras e da bateria faz seu diferencial dentro do Movimento Cabaçal.

A banda Jumentaparida era uma das mais bem cotadas em termo de público. A juventude identificava-se muito com sua música, talvez por seu caráter mais próximo do rock. Conseguiu realizar um clipe na casa de show Hey How, na cidade de Fortaleza, e lançar um $C D$ homônimo, em sua curta trajetória musical.

Em seu $C D$, único lançado pela banda, constam 14 músicas, cujas letras apresentam estrofes mais longas. Estão divididas, em sua maioria, em três ou quatro. A melodia prima por um som em que predominam as guitarras, os baixos e as baterias.

A canção Jumentaparida, que carrega o mesmo nome da banda, apresenta em sua letra uma proposta muito clara acerca da realidade do Nordeste: o sertão e o êxodo rural. Nesta banda, observa-se também a fusão de elementos regionais com aqueles da cultura do rock, com destaque para o timbre destorcido da guitarra: Então, a Jumenta hoje, desembestou/ E o sertão vai ouvir rock"nroll/ Ecoando de todos os lados/ Trazendo o recado para o povo mandou/ Resolvi, bem cedinho me mandei pro sertão/Na paisagem encontro a inspira- 
ção/ A guitarra misturei com o fole/ Peguei hardcore e misturei com o Baião.

A referida banda e Soulzé, entre as quatro aqui pesquisadas, não deram continuidade a seu trabalho, desfazendo-se em 2005. A falta de apoio estatal foi o motivo gerador, segundo seus integrantes, do fim do grupo, que se sentiu desmotivado em seguir a carreira artística.

E, finalmente a última, SoulZé, criada em 1997, originária de Fortaleza, tinha como característica a mistura a levada da música soul aos elementos nordestinos, carregando uma batida diferente das outras às quais me referi anteriormente. Passeiam, também, pelos gêneros samba-funk e o drum'n'bass, na busca por um som diferencial.

Atualmente o Movimento Cabaçal já não se encontra mais no cenário musical cearense. Nos shows não há mais referência a ele e as bandas já não mais se encontram, seguindo, assim, uma trajetória solitária, da produtora Caldeirão das Artes, que ainda faz menção às bandas Dzefinha e Dr. Raiz.

Ao se referirem às suas músicas, se intitulam como Beat Pesado, por beber na fonte da música nordestina e pregar a heterogeneidade cultural. A origem das composições resulta desde mistura do baião até os ritmos contemporâneos. "O jungle se abaioniza e o rock se anordestina nas densas levadas percussivas ". ${ }^{16}$

$\mathrm{Na}$ letra da canção Cyber Cangaceiro $^{17}$, ocorre a fusão do meio tecnológico com o universo nordestino, além da própria proposta da banda em sua denominação.

\section{CONSIDERAÇÕES FINAIS}

Mudanças em todo o mundo acabaram por interferir nas artes e, sobretudo, na cultura de um povo. No caso do Brasil, especificamente, os extremos se acentuam, destacando as regiões Norte e Sul, o que incitou cada vez mais o estudo dos regionalismos. A nação passou a ser vista dividida, buscando captar o todo, através do qual se chega a uma totalidade.

O Nordeste "nasce", então, para o país, em meio a essa dicotomia regional. Segundo a estudiosa Vieira (2000), foi redefinida a questão do espaço regional, com a existência de programas e políticas voltadas diretamente para o Nordeste, o que consolidou sua imagem, por conta da riqueza de crenças, costumes e atitudes peculiares.

Sem dúvida que os meios de comunicação na época - principalmente os jornais - contribuíram para a construção do imaginário coletivo. $\mathrm{O}$ Nordeste manteve uma imagem de região predominantemente inferior, devido às calamidades naturais que the aferraram, como a seca de 1919, em contraste com a modernização urbana de São Paulo, grande pólo econômico e social. Alastra-se, até os dias atuais, a visão de que os estados nordestinos são atrasados, principalmente nas áreas rurais, mais castigadas pelo flagelo da seca.

A "música nordestina", após o processo de construção de um imaginário coletivo que, por longos anos, insistia em defini-la como inferior, agora aparece sob um novo cenário: a cidade. As influências trarão uma nova roupagem à música, que passará a não representar somente o universo rural, mas terá olhos para o mundo futuro.

Percebemos que cada uma destas expressões musicais ocorridas no Ceará apesar de uma proposta singular, havia um objetivo comum: realizar uma música popular, relacionando-a com elementos da modernidade, em seus ritmos, letras e performances. 
Para estes músicos a canção proposta, apesar de ter suas origens e características fincadas no Nordeste, não se propõe a identificar-se apenas como música regional, como muitas vezes é difundida na própria mídia e nos meios de comunicação. A música, segundo eles, é universal. É assim a maneira com a qual os jovens assimilam essa "nova" forma de perceber e se identificar com a "música nordestina".

\section{Bibliografia:}

ANJOS, Moacir dos. Local/Global: arte em trânsito. Rio de Janeiro: Jorge Zahar ed., 2005.

BRANDÃO, Antônio Carlos/ Duarte, Milton Fernandes. Movimentos Culturais da Juventude. São Paulo: Editora Moderna, 1990.

CABAÇOM - O Som do Movimento Cabaçal. Produção: Renee Muringa. Fortaleza: Proaudio Studio 2002/2003.

CANCLINI, Nestor Garcia. Culturas híbridas: Estratégias para entrar e sair da modernidade. São Paulo: EdUSP, 1997.

.Globalização imaginada. São Paulo: Editora lluminus, 2003.

Consumidores e cidadãos: conflitos multiculturais de Globalização. Rio de Janeiro: Editora UFRJ, 2006.

CANEVACCI, Massimo. Sincretismos: uma exploração das hibridações culturais. São Paulo: Studio Nobel, 1996.

CARVALHO, Gilmar de. Tramas da Cultura - Comunicação e tradição. Fortaleza: Museu do Ceará, 2005.

CARVALHO, José Jorge. Transformações da sensibilidade musical contemporânea. IN. Horizontes Antropológicos. /UFRGS. IFCH. Programa de Pós-
-Graduação em Antropologia Social. - Ano 1, n.1 (1995). Porto Alegre: PPGAS, 1999.

COSTA, Jane Meyre Silva. Movimentos artístico-culturais no Ceará: uma interpretação do Movimento Cabaçal. Fortaleza: Universidade Estadual do Ceará, 2004. Monografia de Graduação do Curso de Serviço Social.

DR. RAIZ. Cariri.Ce.Brasil. Arranjos: Grupo Dr. Raiz. Direção de Arte: Marcos Pê. Fortaleza: Proaudio Studio, 2006.

DZEFINHA. Cantos e causos. Produção Executiva: Thais Andrade. Direção musical: Orlângelo Leal. Fortaleza: Proaudio Studio, 2002.

DZEFINHA. Zefinha vai à feira. Produção Executiva: Caldeirão das Artes- Thais Andrade. Direção musical: Orlângelo Leal. Fortaleza: Proaudio Studio. 2005/2006.

HALL, Stuart. Da Diáspora: Identidades e Medições Culturais. Belo Horizonte: Editora UFMG, 2003.

A identidade cultural na Pós-Modernidade. Rio de Janeiro: DP\&A, 2005.

JUMENTAPARIDA. Jumentaparida. Produção: Moisés Veloso e Jumentaparida. Fortaleza: MV Estúdio, 2002.

VIEIRA, SULAMITA. O sertão em movimento: a dinâmica da produção cultural. São Paulo: Annablume, 2000.

\footnotetext{
1 Graduada em Serviço Social e Mestra em Políticas Públicas pela Universidade Estadual do Ceará. Atualmente é professora substituta do curso de serviço social pela referida universidade. Este artigo representa parte da pesquisa de dissertação de Mestrado apresentado em 2007, pela Universidade Estadual do Ceará.
}

\footnotetext{
2 A Tropicália foi alvo de muitas críticas. Por suas atitudes provocadoras foi odiada pela direita, e por não ter um
} 
caráter de protesto também foi criticada pela esquerda. Seu desfecho se deu no final da década de 60. Brandão e Duarte resumem esse período histórico, de engajamento da juventude na cultura e na política brasileira: "Nesse contexto, a cultura jovem dos anos 60 , no Brasil, chegou ao final da década enfrentando duas novas questões. De um lado, a tentativa de manter uma produção cultural engajada, motivada pela idéia de revolução e transformação social, tal como fora equacionada até 1964 (...), de outro lado, a participação na indústria cultural, identificada como uma espécie de "traição" à cultura nacional, pois era tida como uma forma de cooptação utilizada pelo regime militar ao capital estrangeiro. A esse impasse, o Tropicalismo tentou responder de forma original. Entre a exigência de uma cultura politizada e a solicitação de uma cultura de consumo, optou pela tensão que poderia ser estabelecida entre esses dois pólos de concepção estética e política" (Brandão e Duarte, 1990:74). Apesar de compreender que o hibridismo vem-se instalando na música brasileira há muito tempo, foi através da figura desse movimento que houve uma explosão no Brasil em termos de experimentação musical, trazendo à tona uma nova forma de criar música. Desapegado de valores tradicionalistas, a Tropicália surge com a proposta de fundir gêneros e estilos musicais, trazendo para a época novos conceitos e tendências e aliando o tradicional ao moderno. O Tropicalismo representou uma nova linguagem da música popular brasileira, partindo da "tradição" da música, aliada a elementos da modernidade. Essa iniciativa de unir elementos foi bastante criticada na época pelos que apostavam num movimento para a construção de uma identidade nacional.

3 Este depoimento foi retirado do jornal O Povo, do dia 14 de março de 1999, através do site www. noolhar/vidaearte

${ }^{4}$ Músico cearense, José Ednardo Costa Soares, nascido em Fortaleza em 1945, ajudou a organizar o evento Massafeira em Fortaleza, e autor de uma das músicas mais importantes para afirmar a fusão da música com a literatura de cordel "Pavão Misterioso". Retirado do jornal O Povo, no dia 14 de março de 1999, disponível em http//www.noolhar.com.br/vidaearte.

\section{${ }^{5}$ Poeta cearense.}

${ }^{6}$ Retirado do Jornal O Globo, entrevista realizada por Ana Maria Bahiana, em 1982, com a atemática "Uma Luz no fundo das trevas".
${ }^{7}$ Entrevista concedida ao jornal O POVO no dia 12 de abril de 2004, disponível em http// www.noolhar.com. br/vidaearte.

${ }^{8}$ É o conjunto musical mais típico do interior cearense, especialmente na região do Cariri. Tem origem perdida no tempo, mas se desenvolveu e adquiriu peculiaridades próprias entre o povo do Cariri. Há também uma influência indígena, devido ao uso de instrumentos típicos como os pífanos (ou pífaros). A Banda compõe-se de quatro elementos, que tocam zabumba, pífaros e uma caixa. A mais conhecida é a Banda Cabaçal dos Irmãos Aniceto, localizada no Crato. Toca quase toda espécie de música popular: antiga, regional, religiosa e carnavalesca. O ritmo é o baião, característico dos pés-de-serra do Cariri. Apresenta-se, em geral, em festividades de cunho cultural, artístico e religioso. Disponível no site http://www.turismo.ce.gov.br/atrativos_folclore.htm.

${ }^{9}$ Referente ao dia 25 de agosto de 2003

10 Assunto sobre o qual me deterei de uma forma mais aprofundada posteriormente.

${ }^{11}$ Também chamada Banda de Couro, é o conjunto musical mais típico do interior cearense, especialmente na região do Cariri. Originou-se no meio dos escravos africanos, mas se desenvolveu e adquiriu peculiaridades próprias entre o povo do Cariri. Há também uma influência indígena, devido ao uso de instrumentos de características indígenas (pífanos e pífaros). A banda compõe-se de 4 elementos tocando zabumba, pífaros e uma caixa. A mais conhecida é a Banda Cabaçal dos Irmãos Aniceto, localizada no Crato. Toca quase toda espécie de música popular: antiga, regional, religiosa e carnavalesca. O ritmo é o baião, característico dos pés-de-serra do Cariri. Apresenta-se, em geral, em festividades de cunho cultural, artístico e religioso. Disponível no site http://www.turismo.ce.gov.br/atrativos_folclore.htm.

12 A Banda, originária do Crato, é composta por cinco integrantes de uma mesma família: a Lourenço da Silva. São dois pifeiros, Raimundo e Antônio, o zabumbeiro Adriano, filho de Antônio, Jeová na caixa, e Cícero nos pratos. Segundo Assumpção essa Banda representa a "tradição" oral perpertuada pelas diferentes gerações, descendente direto dos índios Cariri. Tem uma relação muito estreita com os elementos da natureza, em virtude de sua própria origem, os índios 
Cariris. Além dessa formação musical, apresentava-se através de movimentos performáticos, imitando animais, em seus shows por todo o país. Iniciavam os eventos, em algumas participações, nos shows do Movimento Cabaçal. Disponível no site http// www.revistaangulo.com.br em 15.jan.2004

${ }^{13}$ Aos 20 anos de idade chegava à cidade de Juazeiro o paraibano José Lourenço Gomes da Silva, em busca de orientação do padre Cícero. Este recomendou que fizesse uma penitência durante algum tempo e que depois voltasse. No seu retorno disse que tinha uma missão. Mandou que se situasse no sítio Baixa Dantas, onde o padre mandaria os romeiros mais desvalidos, fugitivos de perseguições. O beato tornou-se pessoa de grande confiança de Padre Cícero. Após vários problemas, Padre Cícero perde o sítio e loca José Lourenço e seus seguidores na fazenda Caldei- rão. Em pouco tempo é fornecedor de mão- de-obra, além de fertilíssima propriedade. Após a morte de Padre Cícero, Caldeirão é atacado por oficiais da polícia, devido ao receio de sua expansão. O local é saqueado e incendiado. (Souza:1994)

${ }^{14}$ Segundo entrevista do vocalista Júnior Boca para esta pesquisadora.

15 Entrevista concedida pela Banda ao Jornal O Povo de 14 de Junho de 2007, tendo como título da matéria "O balaio (High Tech) da Zefinha", de Amanda Queirós.

${ }^{16}$ Retirado do site da banda www.soulze.com.br no dia 06/09/2006

17 Cyber Cangaceiro (Retirado do site da banda www. soulze.com.br no dia 06/09/2006).

\section{Contato:}

Jane Meyre Silva Costa

- janemsc@yahoo.com.br

Artigo recebido em Abril de 2012

Artigo aprovado em Julho de 2012 